\title{
Digitalized Versus Interpreted Biology Instructions for Deaf Learners: Implications for a Technosociety
}

\author{
Olufemi T. Adigun \\ Dumisani R. Nzima \\ Department of Educational Psychology and Special Education, \\ Faculty of Education, University of Zululand, South Africa
}

DOI: https://doi.org/10.36941/jesr-2020-0104

Abstract

\begin{abstract}
Deaf learners have strived to enrol in science-related subjects but barriers towards effective teaching and learning have contributed to low performances in science-related subjects. Although previous studies have affirmed that learners' attitude towards scientific instructions and pedagogical strategies used by science teachers creates barriers to effective learning and expected learning outcomes, but gaps still exist in the use of digital components in learning outcomes of deaf learners. Therefore, this study, determined the moderating effects of onset of deafness on the attitudes of deaf learners towards Biology in Ibadan, Nigeria. Twenty-seven deaf learners were exposed to an 8-week digitalized and interpreted Biology instructions. Data were collected using the Biology Achievement Test before and after the treatment sessions. The data generated were analysed using the Analysis of Variance at $p<0.05$. The results revealed that deaf learners in the digital Biology class performed better than their peers in the interpreted Biology instructions. Variations in the attitude toward Biology based on onset of hearing loss were observed. Based on the findings, recommendations were made to adequately prepare the deaf for a technologically-driven inclusive society.
\end{abstract}

Keywords: Digitalized and interpreted instruction, deaflearners, Biology, onset of deafness

\section{Introduction}

Science education has shaped human interaction with and reaction to the environment. Until now, discussions at various sustainable developmental fora centred on how the environments have continuously been polluted and degraded, with increasing health challenges as well as increased incidents of natural disasters. The perceived effects of global warming have necessitated the need for scientific orientation, skills and knowledge in learners irrespective of their disabilities. Hence, the need to expand the scope of teaching and learning sciences, especially biological science, is expedient. Biology is a scientific subject that exposes learners to living and non-living components vis-a-vis how they interact within the ecosystem. Its inclusion in the school curriculum is meant to assist learners develop and acquire necessary skills and attitude that informs responsible activities for a safer habitat. Therefore, based on the need for safer environment, there is an increase enrolment rate of learners in Biology classroom compared to Chemistry or Physics, because learners found the subject to be simple and its concept appeals to all senses (Ofoegbu, 2003). Unfortunately, learning outcomes (achievement and attitude) in Biology is not significantly different to what is observed in other science subjects, especially among deaf learners (Ofoegbu, 2003). 


\section{Literature Review}

Learners who are deaf have the potential to respond to stimuli through their sense organs, except through the organ of hearing. They have a hearing loss that is so severe that processing linguistic information through the organ of hearing is extremely unachievable either with or without amplification device. Hence, they are largely not privy to incidental information via auditory-verbal means. Apart from the difficulties experienced in hearing, deaf learners, irrespective of the onset of deafness, are capable of achieving better academic outcome but, currently, they are faced with uneven academic treatments coupled with learning environment filled with low expectations of their strengths, particularly in sciences (Parkin, 2010; Adigun, 2017). Hence, the tendency to show less concern to science education may not be far from being high. This is partly because both prelingually and postlingually deaf learners are confronted with complex issues in the field of science education, which include unavailability of adequate classroom resources and appropriate textbooks, test preparedness and assessment modification, challenges of preparing deaf learners for standardized examinations, inadequacies in the preparation and training of science teachers with required knowledge of the characteristics of deaf learners as well as lack of sign language interpreters with science background. Sign language is a complex but complete language that engages the activities of the hands combined with facial expressions and postures in a signing frame to form signs which represent words and sentence structures needed for effective communication. Although studies have appreciated the use of sign language in teaching deaf learners (Nussbaum, Waddy-Smith \& Doyle, 2012; Jameel and Bibi, 2016), the impact of using sign language on the attitude of deaf learners toward science instructions is a concern for researchers.

Attitudes of students toward science subjects have generated debates among researchers. Hirca, Çalik and Seven (2011) view instructional techniques as a determinant of attitude, while Flores and Rumjanek (2015) conceive school climates and family involvement as factors that influence learners' attitudes toward sciences. Students' attitudes toward sciences, irrespective of gender, have been studied. However, such studies focused mainly on science, in general, with less attention given to Biology among learners who are deaf (Osborne, Simon \& Collins, 2003). This can partly conceal the attitude and interest of deaf learners, because science is not viewed as a homogeneous subject in relation to gender. Francis and Greer (1999) argue that boys show more positive attitudes toward science than girls and more negative attitudes are associated with the physical sciences rather than biological sciences. Dawson (2000) compared changes in Australian students' interests and attitudes over 20 years and found that girls' preferences in Biology gave them a lead in human biology and general biology, but boys were greatly interested in earth sciences, with better learning outcomes in earth sciences than the girls.

Roald and Mikalsen (200o) assert that, irrespective of gender, conceptions of scientific facts of young deaf learners are similar to those of their hearing peers, but knowledge and attitude of deaf learners towards sciences significantly differ in depth and understanding. For deaf learners, there is a wide gap in attitude towards science, scientific reasoning, experience, ability to form the mental model necessary for the integration and understanding of scientific facts and idea. Although it is argued that teachers who can communicate in sign language and sign language interpreters could assist to stand in gaps to enhance learners' attitude to sciences, reasoning, knowledge and understanding, classroom observations and informal interaction with teachers, supported by the findings of Mukhopadhyay and Moswela (2010), revealed a contrary finding. Mukhopadhyay and Moswela state that teachers of the deaf struggle to teach science-related concept, as it is somewhat difficult for the teachers to explain such scientific terms and concepts without adequate training. Mukhopadhyay and Moswela (2010) assert that sign language is not appropriate and proper for teaching science concepts to deaf learners owing to its linguistic perspectives and other missing features of scientific morphology and syntax. The use of sign language in classroom learning environment is believed to be the most effectual means of achieving higher level of deaf literacy, curriculum knowledge and positive dispositions (Wilbur, 200o) but not in science subject 
(Mukhopadhyay \& Moswela, 2010). Stewart and Kluwin (2001) state that, as a result of factors such as curriculum differentiation, pedagogical dilemma, support materials and difficulties experienced by teachers/instructors in giving adequate scientific information to deaf learners through sign language, students with hearing impairments reported difficulties in constructing their knowledge of science with a low scientific interest. These challenges might have possibly led to the abysmal performances and lack of interest in science subjects by deaf learners.

According to Tang and Yang (2007), classroom communication via sign language appears to be the best between the teacher and the deaf students. However, combining two modalities of communication, such as kinesthetic and tactile, with auditory and visual information greatly improves learning (Daniels, 2001). Roald (2002) claims that reading of the textbook after brief introduction through sign language promotes the understanding of scientific concepts among deaf students. Similarly, Land and Steely (2003) aver that web-based contents and interactive multimedia teaching yield significantly and positively strengthen the knowledge gained in science for deaf students as compared to traditional classroom experiences. Corroborating Land and Steely (2003), Akram, Mehboob, Ajaz and Bashir (2013) emphasize that the abysmal low level of interest in science subjects among deaf learners is caused by linguistic difficulties, poor science facilities and conventional teaching mode, that is sign and writing on the board.

Studies (Arsyad, 2010; Flores \& Rumjanek, 2015) have underplayed the use of the conventional approach to teaching scientific concepts in the digital age, especially for persons with disabilities. In particular, Arsyad (2010) states that science phenomena are factual, with a cause-effect relationship which requires a quite complicated link in the use of sense organs for gathering of information. Therefore, it is expedient for teachers to use learning tools to ensure that science classrooms and concepts for the deaf appeal to their senses and stimulate their interest. The digital media that shape and refine information will serve the purpose of integrating deaf learners into the world of science. To date, technology in education remains an important issue of discourse in view of its implications for rapid access to information, teaching, learning and impact on emotional, physical and social development of young adults. Although there is a connection between learning potential and application of technology, Higgins, Xiao and Katsipataki (2012) remark that the connection between the two concepts is fairly consistent. Other studies have indicated a stronger association (Somekh et al., 2007; Flores \& Rumjanek, 2015).

The introduction of computer application into the educational process has grossly benefitted the teaching and learning process. Through digital instruction, educative information is shared amongst all concerned via audio-visual means. Audio-visual information, particularly visual information-rich contents from the digital technologies appeal more to learners whose sense of hearing is defective. Thus, programmed instructions on digital technology greatly assist learning potential and styles of learners who can only learn through visual means. Opportunities created by digital technologies avail deaf learners assess to self-learning, repetition without pressure, motor skills and visual motor coordination, satisfaction, regulated and unregulated time to learn with prompt feedback, besides enhancing disposition towards scientific instructions. In other words, teaching through digital means allows learners to be responsible for their own learning outcomes. In comparison to the traditional classroom, introduction of computer tools for teaching enables learners, irrespective of disabilities, to gain access to new vista of learning and expanding their horizons.

Jimmy (2007) and Bagabas (2016) note that digital technologies assist learners who are deaf in understanding difficult phenomena with increased degree of motivation to learning and improved academic performance. Oramas, Moreno and Chiluiza's (2006) and Mortenson's (2009) studies on the efficacy of digital technology on deaf students' abilities in receptive and expressive sign language revealed that the participants assessed using techno-visual aids scored higher than the group not exposed to the media. A descriptive survey by Moursi (2013) presents the advantages of using computer programs towards the development of academic inclination and achievement of students with hearing impairment. 


\section{Statement of the Problem}

The increase in poor learning outcome of learners in Biology is becoming alarming with a great discrepancy between their scores in learning outcome and those of their hearing peers. This difference among deaf learners and their hearing peers is as a result of communication difficulties. Owing to deprivations in communicative potential, deaf learners have insufficient opportunities to incidental learning and are thus withdrawn from orally rich activities. Withdrawal has negative impacts on the attitude of deaf learners towards studying Biology. Although one might expect that teachers and sign language interpreters could help fill the gap in students' knowledge, the interpreters of most teachers of deaf learners find it difficult to express some basic biological and environmental concepts effectively using sign languages. Therefore, there is the need for science teachers to develop activities to encourage active learning by digitalizing their instruction in order to equip deaf learners with the required scientific skills and attitude. This study, therefore, examined the impact of digitalized instructions and interpreted instruction on the attitude of deaf learners towards Biology in Ibadan, Nigeria.

\section{Materials and Method}

\subsection{Study approach}

This study adopted a quasi-experimental design and "Non-equivalent Control Group Design" based on the causal relationship between the variables of interest. Two groups of participants were created for the study: The experimental group and the control group. The experimental group was exposed to Biology instructions through computer instructional package and sign language, while the control group was exposed to teaching through sign language and lip reading, according to the traditional method of classroom instruction.

\subsection{Participants}

The participants were 27 deaf learners in senior secondary school II from two different public senior secondary schools for the deaf in Ibadan, Oyo State, Nigeria who were grouped into the experimental groups (digitalized instruction) and the control group (sign language interpreted instructions). The participants were 15 (9 males, 6 females) and 12 ( 5 males, 7 females) prelingually and postlingually deaf exposed to an 8-week conventional and digital teaching in Biology, respectively. The participants were of close economic, social and cultural levels in Ibadan, as shown in Table (1).

Table 1: Description of the participants according to onset of deafness and gender

\begin{tabular}{|l|c|c|}
\hline & Prelingually Deaf Learners & Postlingually Deaf Learners \\
\hline Mean Age (Std Dev.) & $16.05(0.40)$ & $16.0(0.82)$ \\
\hline Male & 8 & 6 \\
\hline Female & 5 & 8 \\
\hline Total & 13 & 14 \\
\hline
\end{tabular}

Note: Standard deviation values in parenthesis

\subsection{Measurements}

Biology Achievement Test (BAT) developed by the researcher was used to test the knowledge of the participants in Biology. Using the Kuder-Richardson Formula $\left(\mathrm{KR}_{2 \mathrm{o}}\right)$, the BAT was found to be reliable at 0.67 . The BAT consisted of 50 multiple choice test items developed based on the Blooms' taxonomy. The BAT was used to determine the pretest and posttest scores of the participants. Also, 
participants' attitudes were measured with the Attitude towards Biology Scale $(\alpha=0.73)$. The scale is a forty-item scale designed on a four-point Likert scale, ranging from strongly agree (SA), agree (A), disagree (D) to strongly disagree (SD).

\section{Results}

Hypothesis 1: There will be a significant interaction effects between treatments and onset of hearing loss of the participant on their attitude towards Biology.

Table 2: Summary Analysis of Covariance of Posttest Attitude Acores of treatment and Onset of hearing loss

Tests of Between-Subjects Effects

Dependent Variable: POSTTEST ATTITUDE

\begin{tabular}{|l|c|c|c|c|c|}
\hline Source & Type III Sum of Squares & $\mathrm{df}$ & Mean Square & $\mathrm{F}$ & Sig. \\
\hline Corrected Model & $2758.555^{\mathrm{a}}$ & 3 & 919.518 & 5.078 & .008 \\
Intercept & 318647.779 & 1 & 318647.779 & 1759.608 & .000 \\
Trtgroup & 1114.268 & 1 & 1114.268 & 6.153 & .021 \\
Onset & 56.490 & 1 & 56.490 & .312 & .582 \\
trtgroup * onset & 654.890 & 1 & 654.890 & 3.616 & .070 \\
Error & 4165.075 & 23 & 181.090 & & \\
Total & 378401.000 & 27 & & & \\
Corrected Total & 6923.630 & 26 & & & \\
\hline
\end{tabular}

a. R Squared $=.398$ (Adjusted R Squared $=.320$ )

Table 2 shows that there was no significant interaction effect of treatment and onset of hearing loss on the attitude of deaf learners towards Biology $\left(\mathrm{F}_{(1,26)}=6.15, \mathrm{P}>0.05 ; \eta^{2}=0.21\right)$. Therefore, the null hypothesis was accepted. This implies that onset of hearing loss has no effect on the attitude of students with prelingual or postlingual hearing loss who are exposed to digitalized instruction and interpreted instructions towards Biology.

Research question 1: Will there be a significant mean difference in the pretest and posttest attitude scores of deaf learners in the two learning situations?

Figure 1 indicates that participants in the digitalized instruction had a significantly higher posttest mean score of 17.71 in their attitude towards Biology than the participants in the interpreted Biology instruction group, who had a posttest mean score of 9.36. The posttest means scores of 17.71 and 9.36 for digitalized and interpreted instruction were better than the pretest scores of 7.50 and 4.43 obtained by the learners in the digitalized instruction group and those in the interpreted instruction group, respectively. Although the study revealed a gain in the attitude of the participants towards Biology at the posttest, a significant improvement in attitude was found among participants exposed to the teaching.

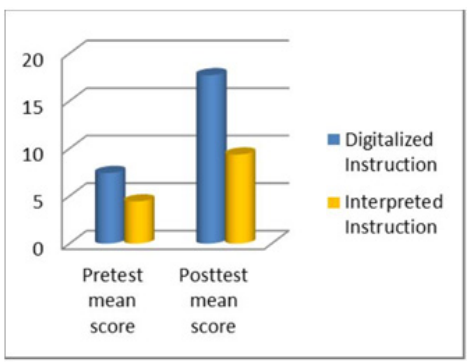

Figure 1: Diagrammatic representation of Mean difference in the mean scores of the participants based on the treatments 
Research question 2: Will there be any significant mean difference in the attitude scores of learners who are prelingually deaf and those postlingually deaf under the two different learning conditions?

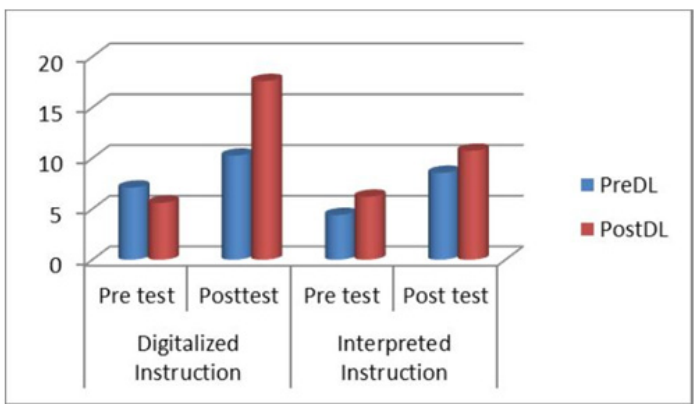

Figure 2: Prelingual and postlingual performance on the attitude towards Biology Pre-test and Posttest in the two learning conditions.

Figure 2 indicates the gain in the attitude of the participants towards Biology based on their onset of hearing loss. The result showed that the prelingually deaf learners who were in the interpreted instruction group had a posttest attitude score of 8.56, while their counterparts in the digitalized instruction group had a posttest attitude score of 10.25 . The postlingually deaf participants at the digitalized group had a posttest attitude means score of 17.60 and those in the interpreted instruction group had a posttest attitude towards Biology means score of 10.73. Although there was a gain in development of positive disposition towards the Biology was observed at posttest for both prelingually and postlingually deaf learners, a substantial positive disposition towards the concept was observed among the postlingually deaf learners who were exposed to digital instruction.

\section{Discussions}

This study determined the effects of digitalized and interpreted instructions on the attitude of deaf learners towards Biology vis-à-vis how onset of deafness and gender of learners can moderate the attitude of these learners. The findings from the study revealed that the instructional strategies had no obvious interactive effects of onset of deafness on attitude of learners towards learning of Biologyrelated concepts. This means that onset of deafness does not determine learners' attitude towards teaching and learning. In other words, the effects of deafness on learning, social interaction, psychological well-being and how deaf learners perceive concepts are the same for both the prelingually and postlingually deaf. This finding is in tandem with Gudyanga, Wadesango, Eliphanos and Gudyanga (2014), who describe communication experience as the major factor that motivates deaf learners. They note that, when deaf learners have a good grasp of a content of discussion, there is the likelihood of having good disposition towards the subject matter under discussion. Similarly, Parkin (2010), Hirca et al. (2011), Flores and Rumjanek (2015) note that the psychological attributes of deafness have association with the individual and how such individual adjusts to society. In particular, Flores and Rumjanek (2015) remark that teaching strategies and teachers' ability to communicate effectively and efficiently may arouse the interest of deaf learners towards learning. As noted by Gudyanga et al. (2014), social maturity of deaf learners is somewhat lower than it is for their hearing peers and this may significantly influence their interaction even in a classroom setting.

This study confirmed the efficacy of teaching learners who are deaf through instructional media that appeal largely to the sense of sight. An instructional medium with an interface which deaf learners can conveniently manipulate is crucial. It further exposed the gain in the attitude of the participants exposed to the digitalized teaching strategy towards Biology. This finding is in support of 
Mwanyuma (2016), who states that learners with hearing disabilities can only fully participate in academic instructions which appreciate their loss of sense of hearing but complement the loss with instructions and communications that fully appeal greatly to their sights. Therefore, as argued by Mwanyuma (2016), for learning to be meaningful, real and permanent, academic instructions for learners with hearing loss must be facilitated with visual aids and communication approaches that complement the use of sign language for classroom instructions. This finding negates the view of Tang and Yang (2007), Kurz, Schick and Hauser (2015) and Jameel and Bibi (2016) that the provision of interpreters is adequate to effectively teach science to the deaf. This is because many sign language interpreters in science classrooms lack the required scientific knowledge and adequate signed vocabulary items that present science terms as they are supposed to be interpreted (Solomon, 2012). This has contributed to the observed challenges faced by deaf learners in science classrooms (Mukhopadhyay and Moswela, 2010). Furthermore, this study confirmed the Napier and Barker's (2004) assertion that deaf students, irrespective of their onset of deafness, find it difficult to completely comprehend academic instructions being passed through interpreted instructions alone.

This study observed that the postlingually deaf learners at the digitalized group had significant positive gain in disposition towards the Biology compared to the prelingually deaf learners. This finding may have been as a result of the fact that postlingually deaf learners have previously had an opportunity to appreciate and react to sound stimuli. In other words, there is the tendency that knowledge gained through sound perception abilities before the loss in hearing potential contributed to their established attitude towards Biology. However, the impact of deafness on their classroom psychosocial needs remains the same. This finding buttresses Margolis (2001), who note that speech and speech-perception abilities and skills are very much unlikely for prelingual deaf children even when fitted with assistive listening devices. Margolis claims that language is an essential ingredient of scholarly attitude which is missing in more than $90 \%$ of prelingual deaf learners. Hence, it can be difficult for prelingual deaf learners to conveniently have the required language and vocabulary skills to attain a high reading level. They may, therefore, have difficulties in developing the potential to use and understand abstract concepts.

\section{Implications of the Study for a Technosociety}

Individuals who are deaf are daily striving to be the best. Although they have difficulties in language acquisition and use, they contribute to socio-cultural and economic development. Hence, they must be seen as essential actors that contribute to the growth and development of society. This means that, government at all levels should provide for deaf learners an all-inclusive classroom where effective and efficient teaching and learning of science for the deaf can be easily achieved. The main essence of this relates to the Convention on the Rights of Persons with Disabilities, to which the several African government is a signatory. Essentially, as the world changes rapidly into a technologydriven economy through the instruments of the Fourth Industrial Revolution, the deaf should be equipped with the needed scientific skills and knowledge with which they can function in a technosociety. Hence, no effort should be spared to train and retrain teachers of the deaf in pedagogies that integrate technological application into the teaching and learning process of the deaf. Sign language interpreters with scientific orientations should be allowed to interpret in science classroom. The conference of sign language interpreters, in collaboration with science teachers, should develop culturally fair scientific concepts in sign language, which should be equally disseminated among potential users.

\section{References}

Adigun, O. T. (2017). Effects of computer-assisted instruction and concept mapping on the academic achievement of students with hearing impairment in Ecology in Ibadan, Oyo State, Nigeria. Journal of Issues and Practice in Education, 9(1),123-146. 
Akram, B., Mehboob, R., Ajaz, A., \& Bashir, R. (2013). Scientific Concepts of hearing and deaf students of grade VIII. Journal of Elementary education, 23(1), 1-12.

Arsyad, A. (2010). Media Pembelajaran. Jakarta: PT. Raja Grafindo Persada.

Bagabas, H. A. (2016). The Effectiveness of Computerized Instructional Packages on Concept Acquisition and Improving Academic Achievement among Female Deaf Students in KSA. Journal of Education and Practice, 7(21), 65-71.

Daniels, H. (2004). Cultural historical activity theory and professional learning. International journal of disability, development and education, 51(2), 185-200.

Dawson, R. (2000). Knowledge capabilities as the focus of organisational development and strategy. Journal of knowledge management, 4(4), 320-327.

Flores, A. C. F., \& Rumjanek, V. M. (2015). Teaching Science to Elementary School Deaf Children in Brazil. Creative Education, 6, 2127-2135. http://dx.doi.org/10.4236/ce.2015.620216

Francis, L. J., \& Greer, J. E. (1999). Measuring attitude towards science among secondary school students: The affective domain. Research in Science \& Technological Education, 17(2), 219-226.

Higgins, S., Xiao, Z., \& Katsipataki, M. (2012). The impact of digital technology on learning: A summary for the education endowment foundation. Durham, UK: Education Endowment Foundation and Durham University.

Hirca, N., Çalik, M., \& Seven, S. (2011). Effects of guide materials based on 5 E model on students' conceptual change and their attitudes towards physics: A case for 'work, power and energy unit. Journal of Turkish Science Education, 8 (1), 153-158.

Jameel, H. T. \& Bibi, S. (2016). Benefits of sign language for the deaf students in classroom learning. International Journal of Advanced and Applied Sciences, 3(6); 24-26.

Kurz, K.B., Brenda Schick, B. \& Hauser, P.C. (2015). Deaf children's science content learning in direct instruction versus interpreted instruction. Journal of Science Education for Students with Disabilities, 18(1); 23-37.

Lang, H.G. \& Steely, D. (2003). Web-based science instruction for deaf students: What research says to the teacher. Instructional Science, 31, 277-298.

Margolis, A. C. (2001). Implications of prelingual deafness. The Lancet, 358; 76.

Moursi, A. (2013). The effectiveness of different intensity of visual in computer programs on academic achievement and inclination towards it among middle school hearing impaired students. Journal of Arab Studies in Education and Psychology - Saudi Arabia, 42(2): 11-59.

Mwanyuma, R. (2016). Factors influencing the academic achievement of deaf learners in Kilifi county, Kenya: A case of Sahajanand school for the Deaf. Unpublished Masters Dissertation. Kenya. University of Nairobi.

Napier, J. \& Barker, R. (2004). Accessing university education: Perceptions, preferences, and expectations for interpreting by deaf students. Journal of Deaf Studies and Deaf Education, 9(2), 228-238.

Noureen, A. \& Aziz, R. (200o). A study of interpersonal relationships between teachers and students in the institutions of hearing impaired children. (Unpublished master's thesis). University of the Punjab, Pakistan.

Nussbaum, D., Waddy-Smith, B. \& Doyle, J. (2012). Students who are deaf and hard of hearing and use sign language: Considerations and strategies for developing spoken language and literacy skills. In Seminars in speech and language (Vol. 33, No. 04, pp. 310-321). Thieme Medical Publishers.

Ofoegbu, T.O. (2003). Challenges of implementing Senior Secondary One (SS1) curriculum in Nigeria. Journal of the Science Teachers Association of Nigeria, 38(1\&2) 46-50.

Oramas, J., Moreno, A. \& Chiluiza, K. (2006). Technology for hearing impaired people: A novel use of Xstroke pointer gesture recognition algorithm for Teaching/Learning Ecuadorian Sign Language.

Osborne, J., Simon, S., \& Collins, S. (2003). Attitudes towards science: A review of the literature and its implications. International journal of science education, 25(9), 1049-1079.

Parkin, S. (2010). The positive deviant: Sustainability leadership in a perverse world. Routledge.

Roald, I. \& Mikalsen, O. (200o). What are the Earth and the heavenly bodies like? A study of objectual conceptions among Norwegian deaf and hearing pupils. International Journal of Science Education, 22(4), 337-355.

Solomon, C. Ed. (2012). Workshop for emerging deaf and hard of hearing scientists [Whitepaper]. Washington, D.C.: Gallaudet University. Supported by the National Science Foundation under CNS-o837508 and MCB1232380. Accessed at: http://do it-prod.s.uw. edu/accesscomputingsitesdefaultfilesmanualupload/WhitePaper-Final_Gallaudet_Emerging_Sei_2_15_13.pdf.

Somekh, B., Underwood, J., Convery, A., Dillon, G., Jarvis, J., Lewin, C., ... \& Twining, P. (20o7). Evaluation of the ICT Test Bed project: final report, June 2007.

Stewart, D. A. \& Kluwin, T. N. (2001). Teaching deaf and hard of hearing students: Content, strategies, and curriculum. Boston: Allyn and Bacon.

Wilbur, R. B. (200o). The use of ASL to support the development of English and literacy. Journal of deaf studies and deaf education, 5(1), 81-104. 